Professor John Gibson. By Principal A. P. Laurie, D.Sc.

(MS. received October 26, 1914. Read December 7, 1914.)

JoHn GrBson was born in Edinburgh on May 13, 1855, and was educated at Edinburgh Academy. He afterwards studied chemistry at Heidelberg under Bunsen, Kirchhoff, Kopp, and others, working for five consecutive sessions in Bunsen's laboratory, and graduating in 1876 as Doctor of Philosophy.

On returning to Edinburgh, he became assistant under Professor Crum Brown; later on, in 1881, being appointed chief assistant in the laboratory, where he taught for eleven years. In 1892 he was appointed Professor of Chemistry in the Heriot-Watt College, a post which he held up to the day of his death.

Gibson was, above all things, an analyst. He seems to have developed his original interest in chemical analysis under Bunsen, and to the end of his life he remained in the very first rank of analysts, and always regarded that part of the teaching in the department as of the utmost importance.

As an example of his capacity for analytical research, we cannot do better than take his report on "An Analytical Examination of Manganese Nodules, with special reference to the Presence or Absence of the Rarer Elements," which was published in the Challenger Reports-"Deep Sea Deposits," in 1891, and involved an original research in analytical methods. All those who had the good fortune to be students under him have benefited by his enthusiastic appreciation for, and exact knowledge of, analytical methods.

While in Edinburgh University, Gibson carried out a large number of observations for the Fishery Board on the composition of sea waters, more especially in the North Sea, and he also made an investigation into some of the rare earths. Years of investigation were devoted to the study of these rare earths, and the separation of pure salts from them. Unfortunately, all that ever was published on this subject was a short paper on "Glucinum" in the Transactions of the Chemical Society, 1893.

Gibson always approached the problem of publication with great unwillingness. When once he completed a research, his interest carried him on to fresh investigations, and it was with great difficulty that he could be persuaded to put pen to paper with a view to publication. As a consequence of this, many valuable researches have been lost to science, and this 
is especially the case in connection with glucinum, cerium, lanthanum, and didymium. Large quantities of the minerals were worked up, pure salts prepared, and much work was done, which has no doubt since been confirmed by others, although it may be questioned whether even now all Gibson's results have been re-established.

About the time when the paper on glucinum was published, Gibson started some experiments on the effects of light on such changes as the conversion of chlorine water into hydrochloric acid, the resulting observations being published in a short paper on "Photochemical Action" in the Proceedings of the Royal Society of Edinburgh in February 1897. This was followed by a short paper, "A Preliminary Note on a Characteristic of Certain Chemical Reactions" (Proc. Roy. Soc. Edin., Dec. 1897). The origin of these papers was as follows: In studying the action of light on these mixtures, Gibson discovered the fact that the amount of change depended on whether the final result of the reaction was to increase the electrical conductivity of the solution as a whole or to diminish it, there being a tendency for any such solution to move in the direction of increased electrical conductivity. This led him further to investigate the question as to how far other reactions, apart from those caused by light, were influenced by these conditions.

No particular physical value had been, so far, associated with the electrical conductivity of a system as a whole, and the whole direction of research was proceeding towards experiments on very dilute solutions, with a view to the application of the laws laid down by van't Hoff, Arrhenius, Kohlrausch, and Nernst to the problems of electrochemistry. It was probably for this reason that more attention has not been directed to the very interesting results obtained by Gibson in this direction.

In the preliminary paper already referred to he gives examples of the law that many chemical reactions are governed by the tendency of a solution to develop a state of maximum conductivity in the system, these examples being: the dehydration by hydrochloric acid of hydrated cobaltous chloride; the dehydration of sugar by sulphuric acid; the reduction of chromic anhydride by hydrochloric acid; the oxidation of hydrogen iodide by sulphuric acid; and the oxidation of nitric oxide by nitric acid.

In order to carry these investigations further, he decided to redetermine the conductivity curves of some of the best known acids and salts, and devoted a great deal of time and labour to these measurements, with the result that there can be no doubt that the most exact conductivity curves that we have for hydriodic, hydrobromic, and hydrochloric acids, and 
ammonium bromide, lithium bromide, and sodium bromide, are those determined by Gibson; whilst for these experiments he devised his electrically controlled thermostat, which is a very perfect instrument of its kind.

The main interest of his work, however, remains as before the study of the relation between maximum conductivity and certain types of chemical change. He showed, for instance, the close relation between this and the precipitation of salts from solution by hydrochloric acid; the behaviour of aqueous solutions of hydrogen chloride towards dissolved oxygen and dissolved chlorine respectively; the oxidation of hydrogen chloride in aqueous solution by chromic acid; the action of hydrochloric acid as an esterifying agent; and the action of hydrogen chloride on acetaldehyde, aldol, and crotonaldehyde, and of hydrochloric acid on cobalt chloride. In addition, he investigated the decomposition of aqueous solutions of hydrogen iodide; the behaviour of nitric acid when exposed to light; and, in more detail, the action of sulphuric acid on sucrose and on formic acid. In all these cases he proved quite definitely that the limit to which the reaction was carried was fixed by the point at which the system as a whole reached its maximum conductivity, and that many reactions were reversed on each side of this maximum conductivity point, proceeding in opposite directions when once the maximum of the curve had been passed.

It is, of course, evident that there are a large number of reactions which are not governed by this condition, and this is one of the reasons why for many years Gibson hesitated to publish his results, as he wished to get some definite law by which he could distinguish between reactions which were governed by the maximum conductivity and those that were not.

It is probably safe to say from his results that all chemical systems which are electrolytes tend towards the point of maximum conductivity, although there may be other forces at work which are sufficiently powerful to conceal this tendency; but whenever we are dealing with balanced reactions in which a very small change of conditions will make the reaction proceed the other way, we find the maximum conductivity of the system is the governing condition. There can be no doubt that we have therefore to look for the widest application of this principle when dealing with plant and animal life, where we have such a delicate balance constantly occurring between two possible directions of chemical change.

Gibson has shown the application of his theory to the change from sugar to starch, and again from starch to sugar, in the leaf of the plant, and he also made a considerable number of experiments-which, un- 
fortunately, will now never be published-on the influence on enzymatic reactions of the same condition. His experiments on mustard powder and on crushed bitter almonds have already been published in the paper on "The Significance of Maximum Specific Electrical Conductivity in Chemistry" (Trans. Roy. Soc. Edinburgh, xlviii, Part I, No. 6). These will be found well worthy of study by those who are interested in plant chemistry and in enzymatic changes. It is certainly open to question whether one of the controlling conditions of enzymatic reactions will not be found to be the nature of the mineral salts that are present, and the amount of dilution or concentration required to bring the solution of the salt to its maximum conductivity point.

John Gibson was elected a Fellow of the Royal Society of Edinburgh in 1877, and twice served as a member of Council, from 1892 to 1894 and from 1897 to 1900 . He was of great service to the Council when papers of a chemical nature were under consideration.

Gibson had just completed the fitting up of the new laboratories at the Heriot-Watt College, and had only entered into possession of them for a couple of months, when his death occurred, on January 1, 1914.

It was a peculiarly hard stroke of fate that he should not have had the opportunity of enjoying for a longer time those laboratories in which he had taken so great an interest, and to the completion of which he had for so long looked forward.

The following is a list of his papers published in the Society's Proceedings and Transactions:-

\section{In the Proceedings, R.S.E.}

1. On some Laboratory Arrangements. April 2, 1883 . Vol. xii.

2. On Peroxides of Zinc, Cadmium, Magnesium, and Aluminium (with R. M. Morrison). Read July 5, 1880 : published 1885 in vol. xiii.

3. On Papers by MM. Haas, Clève, and Lecoy de Boisbaudran, on the Production of Peroxides by means of Peroxide of Hydrogen. April 6, 1885. Vol. xiii.

4. The Action of Sodium Carbonate and Bromine on Solutions of Cobalt and Nickel Salts. February 17, 1890. (Abstract.) Vol. xvii.

5. Manganese Deposits in Marine Muds (along with R. Irvine). January 9, 1891. Vol. xviii.

6. On the Chemical Composition of Sea-water. July 3, 1893. Vol. xx.

7. On Photo-chemical Action. February 15, 1897. Vol. xxi.

8. Preliminary Note on a Characteristic of Certain Chemical Reactions. December 6, 1897. Vol. xxii. 
9. On a Thermostat electrically heated and regulated (Title only). February 5, 1900. Vol. xxiii.

10. On certain Relations between the Electrical Conductivity and the Chemical Character of Solutions (Title only). May 6, 1901. Vol. xxiii.

11. Preliminary Note on the Conductivity of Concentrated Aqueous Solutions of Electrolytes. November 6, 1905. Vol. xxvi.

12. Eight papers, with others. June 22, 1908. Vol. xxviii.

13. On an Electrically Controlled Thermostat and other Apparatus for the Accurate Determination of the Electrolytic Conductivity of Highly Conducting Solutions (with G. E. Gibson). June 22, 1908. Vol. xxx.

14. On the Precipitation of Soluble Chlorides by Hydrochloric Acid (with R. B. Denison). August 20, 1910. Vol. xxx.

\section{In the Transactions, R.S.E.}

1. On the Relationship between Concentration and Electrolytic Conductivity in Concentrated Aqueous Solutions. May 11, 1905. Vol. xlv.

2. The Significance of Maximum Specific Electrical Conductivity in Chemistry. Read July 13, 1908: published October 20, 1911. Vol. xlviii. 